\title{
Transvaginal Excision of Rectal Gastrointestinal Stromal Tumor: A Safe Minimally Invasive Approach
}

\author{
Hadiel Kaiyasah Hana Fardan Labib Al Ozaibi \\ Colorectal Unit, Department of General Surgery, Rashid Hospital, Dubai, United Arab Emirates
}

\begin{abstract}
Keywords
Rectal gastrointestinal stromal tumor - Transvaginal excision - Abdominoperineal resection - Local resection . Colonoscopy $\cdot$ MRI pelvis
\end{abstract}

\begin{abstract}
Introduction: Gastrointestinal stromal tumors (GISTs), the specific kit-positive mesenchymal tumors, are rarely found in the anorectum and account for $5 \%$ of all GIST cases. Surgical excision remains the main treatment for anorectal GIST. The available techniques include enucleation transanal excision or sometimes an abdominoperineal resection for large or low tumors. Case Study: We present a middle-aged female with a complaint of intermittent rectal pain for 1 year. Diagnostic workup detected a mass in the rectovaginal septum. A transvaginal excision was performed. Final histopathology showed rectal GIST. On regular follow-up visits, there was no detectable recurrence, and her anal pain disappeared completely. Discussion: Colorectal GIST accounts for only $0.1 \%$ of all colorectal tumors; this infrequency has led to a controversy in its diagnosis and management. Nevertheless, surgery remains a cornerstone element in the management of rectal GISTs. Different resection methods have been described in the literature, ranging from less-invasive approach such as transanal excision to a more radical one like an abdominoperineal resection. As there is no standard ap-
\end{abstract}

proach, choosing which one to perform depends on the tumor size, its location, and the surgeon's preference. Conclusion: Transvaginal excision could be considered a safe minimally invasive approach for low-lying rectal GISTs.

(c) 2021 The Author(s).

Published by S. Karger AG, Basel

\section{Introduction}

Rectal gastrointestinal stromal tumor (GIST) is one of the rare gastrointestinal tumors, accounting for $5 \%$ of all GIST cases and $0.1 \%$ of all colorectal tumors. Male predominance was observed $[1,2]$. Clinical presentation may range from asymptomatic submucosal nodule discovered incidentally on colonoscopy to a large mass causing rectal pain, bleeding, or pressure symptoms. Studies have shown that most colorectal GISTs are high risk, with the possibility of local and distant recurrence. This might necessitate long-term follow-up and adjuvant treatment with tyrosine kinase inhibitors in some cases [2]. Complete resection is one of the most important prognostic factors for rectal GIST. However, sometimes this may result in anal sphincter damage especially in large or lowlying rectal GISTs. This has encouraged adopting a lessinvasive approach like transvaginal excision which showed better functional results [3].
C 2021 The Author(s)

Published by S. Karger AG, Basel

This is an Open Access article licensed under the Creative Commons Attribution-NonCommercial-4.0 International License (CC BY-NC) (http://www.karger.com/Services/OpenAccessLicense), applicable to the online version of the article only. Usage and distribution for commercial purposes requires written permission.
Correspondence to:

Hadiel Kaiyasah, hmkaiyasah@dha.gov.ae 

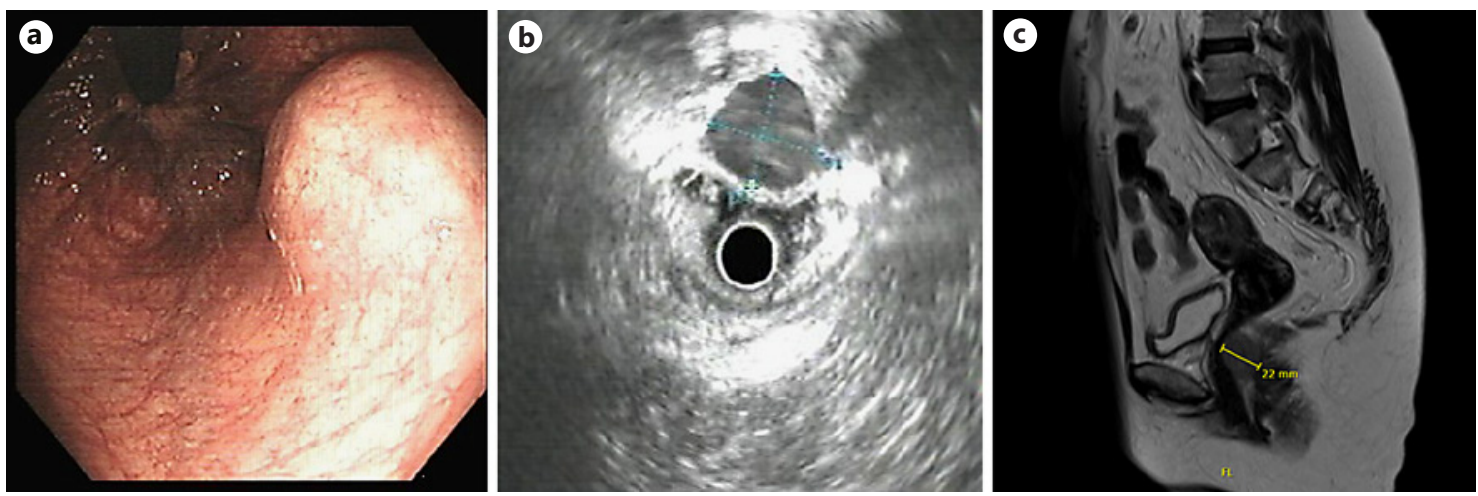

Fig. 1. Diagnostic studies. a Colonoscopy with retroflexion view showing submucosal lesion in the lower rectum with smooth overlying mucosa. b Endoscopic ultrasound image showing a hypoechoic well-circumscribed rectal mass. c Pelvic MRI scan showing hypointense mass in the rectovaginal space.
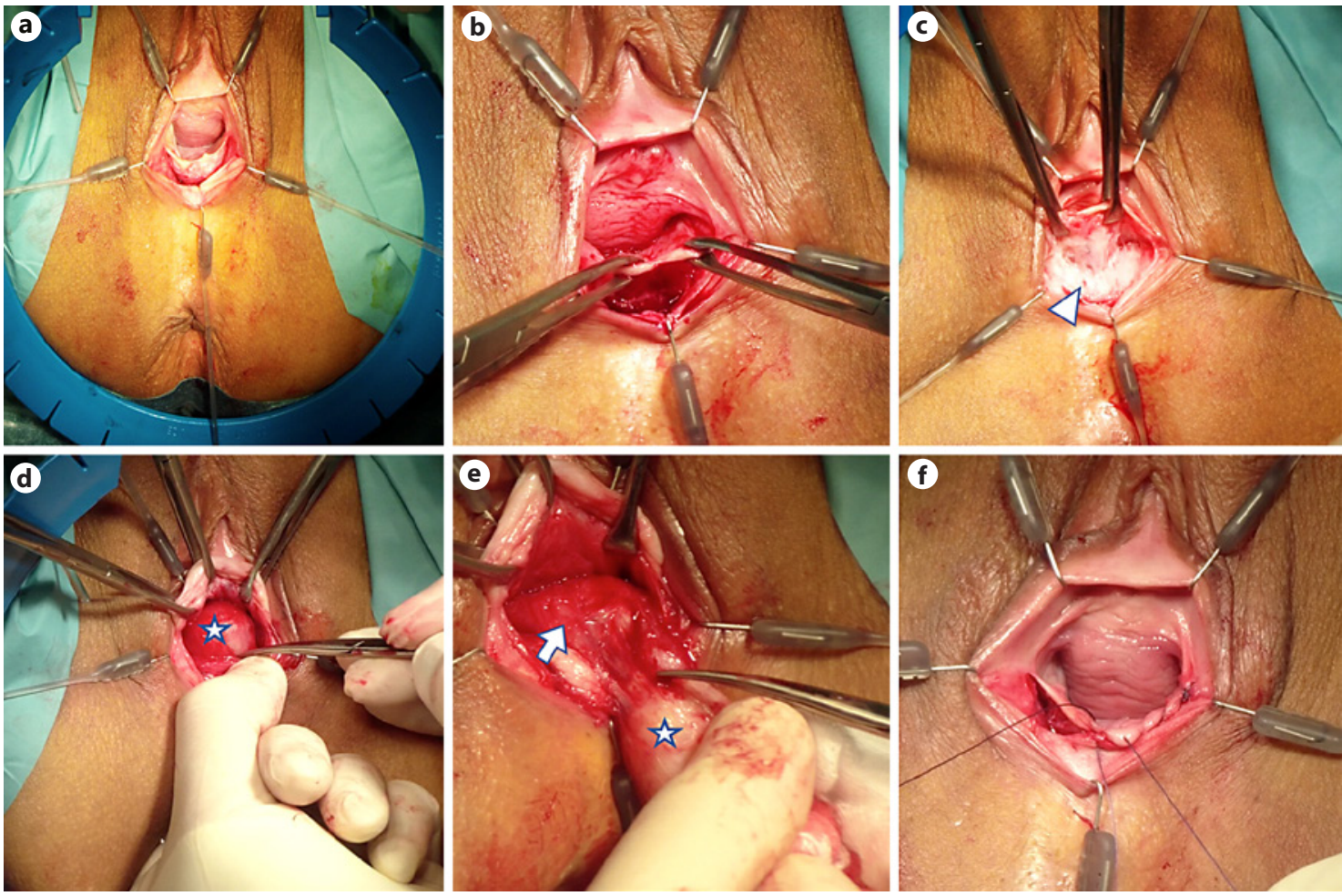

Fig. 2. Transvaginal excision. a Using a lonestar retractor. b Horizontal incision placed in the posterior vaginal wall. c Dissection carried out through the rectovaginal septum (arrowhead). d Tumor is completely exposed (star). e Careful dissection of the tumor (star) from the rectal wall (arrow). f Posterior vaginal wall sutured.

\section{Case Presentation}

We present a 58-year-old female referred to the proctology clinic with a complaint of intermittent rectal pain for 1 year. There was no change in bowel habits or per rectal bleeding. She underwent upper and lower GI endoscopy as a workup for her accompanying abdominal pain. Her colonoscopy revealed a submucosal lesion $2 \times 2 \mathrm{~cm}$ in the rectum $6 \mathrm{~cm}$ from the anocutaneous line with a normal overlying mucosa (Fig. 1a). Endoscopic ultrasound has confirmed the finding of a hypoechoic mass arising from the muscularis propria (Fig. 1b). MRI pelvis showed a hypointense mass in the rectovaginal space (Fig. 1c).

The patient underwent transvaginal excision of the rectal mass (Fig. 2). Final histopathology was rectal GIST with positive markers for CD117 and CD34 with low mitotic figures. Resection margins were free (Fig. 3). After tumor board meeting, adjuvant ther- 


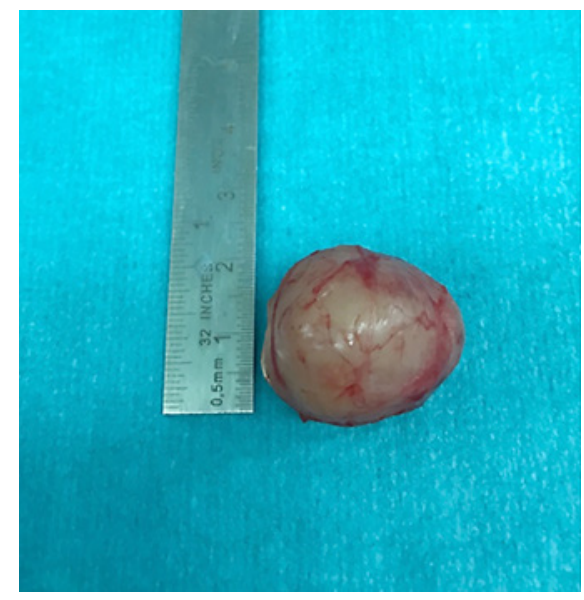

Fig. 3. Gross pathology of the excised mass.

apy with imatinib was not indicated. Postoperatively, she was followed up for 36 months with per rectal examination and endoanal ultrasound twice annually. No recurrence was detected, and she remained symptom free.

\section{Discussion}

GISTs, the specific kit-positive, are the most common mesenchymal tumors of the gastrointestinal tract. They arise from the interstitial cells of Cajal and can occur in any part of the alimentary tract. However, the stomach and small intestine constitute the most common sites, $60 \%$ and $30 \%$, respectively. Colorectal GIST accounts for $5 \%$ of cases; this infrequency has led to a controversy in diagnosis and management $[1,4-6]$.

Rectal GISTs have been reported in adults between the ages of 17 and 90 , with a mean age of 59 years. There is a significant male predominance. Clinical picture may range from a small asymptomatic intramural lump to large ones that may bulge into the pelvis. Patients can present with rectal bleeding, bowel obstruction, or symptoms of prostatitis [2]. Despite being an uncommon presentation, rectal GIST may present with rectal pain as we have described in our case report.

As part of the clinical workup, different imaging modalities can be used in the evaluation of colorectal GISTs, such as computed tomography, magnetic resonance imaging, and endoscopic/endorectal ultrasound. Typically, imaging will show well-circumscribed mass with no infiltration or lymphadenopathy. Colonoscopy may show submucosal swelling with an overlying mucosa looking smooth with no infiltration. Endoscopic ultrasound can show the origin of the tumor from the muscularis propria and the layers of the wall involved by the tumor [7], which will make the diagnosis of rectal GIST highly suspected.

The need for biopsy prior to surgical treatment is debatable. The main concern is the risk of tumor rupture that might lead to dissemination or seeding of the biopsy tract. The only time when biopsy may be deemed necessary is if preoperative therapy is being contemplated for unresectable or marginally resectable tumors. In such cases, core needle biopsy is preferable over fine-needle aspiration, as it may reflect the mitotic rate better $[8,9]$.

Surgery remains a cornerstone element in the treatment of rectal GISTs. It should be considered the initial therapy whenever the tumor is resectable. Intraoperatively, avoiding tumor rupture by careful dissection is vital. Complete surgical resection could be achieved either by enucleation transanal (Park) excision, trans-sacral (Kraske), or sometimes via an abdominoperineal approach. For large or low-lying rectal GISTs, radical excision may induce anal dysfunction with deleterious clinical consequences. Nowadays, transvaginal excision, a less-invasive approach, is preferable whenever feasible [2, $10,11]$.

Upon reviewing the literature, few reports are discussing the transvaginal excision of rectal GISTs. Hellan and Maker [12] first reported that this approach successfully resected larger tumors, saving the patient from a permanent stoma. Later, Hara et al. [13] also reported that transvaginal resection of low anterior rectal lesions may provide a minimally invasive alternative to traditional ultralow anterior resection. A recent publication from China in 2019 by Shizhuo et al. [3] showed that transvaginal excision is a safe reasonable way for the management of low-lying rectal GIST. This technique in resecting rectal GIST is in general less morbid, preserves the anal sphincter complex, and prevents advertent breach in rectal mucosa, which in turn might lead to a fistula development.

In our reported case, we preferred the transvaginal approach, in view of the mass location in the rectovaginal septum. Postoperatively, the patient was followed up for 36 months with per rectal examination and an endoanal ultrasound twice annually. No recurrence was detected, and her pain resolved.

\section{Conclusion}

Rectal GISTs are rare tumors, and complete surgical excision is the mainstay treatment. Transvaginal excision is a safe and feasible minimally invasive approach for tu- 
mors located in the rectovaginal region. This method prevents iatrogenic damage to the anal sphincter and its clinical consequences.

\section{Statement of Ethics}

This case report complies with the guidelines for human studies and conducted ethically in accordance with the World Medical Association Declaration of Helsinki. Ethical approval was not required for this case report in accordance with the Dubai Scientific Research Ethics Committee policies. Witten informed consent for publication of the case report and any accompanied images was obtained from the patient.

\section{Conflict of Interest Statement}

There are no conflicts of interest to declare.

\section{Funding Sources}

The authors did not receive any funding.

\section{Author Contributions}

H.K. contributed to literature review. H.K. and H.F. contributed to medical writing. L.O. contributed to conclusion and final review.

\section{Data Availability Statement}

All data generated or analyzed during this case report are included in this article. Further enquiries can be directed to the corresponding author.

\section{References}

1 Miettinen M, Lasota J. Gastrointestinal stromal tumors-definition, clinical, histological, immunohistochemical, and molecular genetic features and differential diagnosis. Virchows Arch. 2001;438:1-12.

2 Theodoropoulos DG. Gastrointestinal tumors of the colon and rectum. Clin Colon Rectal Surg. 2011 Sep;24(3):161-70.

3 Shizhuo W, Liuyuan, Sha N, Xueting C, $\mathrm{He}$ W, Nannan L, et al. Transvaginal excision of rectal stromal tumors: case reports and a literature review. World J Surg Oncol. 2019 Oct 6;17(1):164.

4 Fletcher CD, Berman JJ, Corless C, Gorstein F, Lasota J, Longley BJ, et al. Diagnosis of gastrointestinal stromal tumors: a consensus approach. Int J Surg Pathol. 2002;10: 81-9.
5 DeMatteo RP, Lewis JJ, Leung D, Mudan SS, Woodruff JM, Brennan MF. Two hundred gastrointestinal stromal tumors: recurrence patterns and prognostic factors for survival. Ann Surg. 2000;231:51-8.

6 Liegl B, Hornick JL, Lazar AJ. Contemporary pathology of gastrointestinal stromal tumors. Hematol Oncol Clin North Am. 2009;23:4968,vii-viii.

7 Ji F, Wang ZW, Wang LJ, Ning JW, Xu GQ. Clinicopathological characteristics of gastrointestinal mesenchymal tumors and diagnostic value of endoscopic ultrasonography. J Gastroenterol Hepatol. 2008;23(8 Pt 2):e318-24.

8 Sepe PS, Brugge WR. A guide for the diagnosis and management of gastrointestinal stromal cell tumors. Nat Rev Gastroenterol Hepatol. 2009;6(6):363-71.
9 Demetri GD, von Mehren M, Antonescu CR, DeMatteo RP, Ganjoo KN, Maki RG, et al. NCCN task force report: update on the management of patients with gastrointestinal stromal tumors. J Natl Compr Canc Netw. 2010; 8 Suppl 2(0-2):S1-41; quiz S42-4

10 Singhal S, Singhal A, Tugnait R, Varghese V, Tiwari B, Arora PK, et al. Anorectal gastrointestinal stromal tumor: a case report and literature review. Case Rep Gastrointest Med. 2013;2013:934875.

11 Shah A, Somu K, Dashore A, Anandh R. Laparoscopic excision of large lower rectal gastrointestinal stromal tumour (GIST): a case report. J Minim Access Surg. 2016;12(3):283-5.

12 Hellan M, Maker VK. Transvaginal excision of a large rectal stromal tumor: an alternative. Am J Surg. 2006;191(1):121-3.

13 Hara M, Takayama S, Arakawa A, Sato M, Nagasaki $\mathrm{T}$, Takeyama $\mathrm{H}$. Transvaginal resection of a rectal gastrointestinal stromal tumor. Surg Today. 2012;42(9):909-12. 